\title{
Peripheral T Cell Lymphoma with Follicular Helper Phenotype, Case Report and Literature Review
}

\section{Katty $\mathrm{AR}^{1 *}$ and Angelica $\mathrm{AR}^{2}$}

${ }^{1}$ General physician, Universidad Autónoma de Bucaramanga-UNAB, Fundacion Oftalmologica de Santander-FOSCAL, Colombia

2Dermatologist, Universidad Autónoma de Bucaramanga-UNAB, Fundacion Oftalmologica de Santander-FOSCAL, Colombia

\section{Case Report \\ Volume 3 Issue 1}

Received Date: October 10, 2018

Published Date: February 12, 2019

DOI: $10.23880 /$ hij-16000135

*Corresponding author: Anaya-Reyes Katty Camila, Universidad Autónoma de Bucaramanga-UNAB, Fundacion Oftalmologica de Santander-FOSCAL, Street 157th \#14-55, Floridablanca-Santander-Colombia, Tel: 3187440657; Email: katty_anaya1103@hotmail.com

\section{Abstract}

T-cell lymphomas are a heterogeneous group of lymphoid neoplasms, with a broad classification; in which the peripheral T-cell lymphoma not otherwise specified, is the most frequently diagnosed subtype, demonstrating the complexity of this hematopoietic neoplasms, the lack of studies and knowledge, which difficult us to understand the behavior of this great spectrum of malignancies. We present the clinical case of a patient with late diagnosis and systemic involvement, with initial diagnosis of psoriasis and progressive evolution of the lesions to tumoral and exophytic nodular lesions predominantly in axillae and groin, associated with cytopenia and hepatic involvement, peripheral T-cell lymphoma with $\mathrm{T}$ follicular helper cell phenotype was confirmed by biopsy and immunophenotypic studies.

This entity was recently described and included in the World Health Organization classification of neoplasms of the hematopoietic and lymphoid tissue updated in 2008. It is a rare entity difficult to diagnose, since it shares clinical and histological characteristics with the great variety of peripheral T-cell lymphoma not otherwise specified, mainly with angioinmunoblastic T-cell lymphoma, whose histological findings, cell markers and immunohistochemistry, have allowed to characterize it as an independent variant.

Keywords: T-cell Lymphoma; Peripheral T-cell Lymphoma; Lymphoma; Non-Hodgkin; Follicular T Cell Lymphoma; Follicular Helper T-cell

Abbreviations: PTCL: Peripheral T-cell Lymphoma; PTCL-NOS: Peripheral T-cell Lymphoma Not Otherwise Specified; EBV: Epstein Barr Virus; AITL:
Angioimmunoblastic T-cell Lymphoma; THF: T follicular Helper Cell. 


\section{Introduction}

T-cell lymphomas are a group of lymphoid neoplasms with systemic involvement and aggressive behavior that includes disseminated, ganglionic, extranodal and cutaneous forms [1]. Peripheral T-cell lymphoma-not otherwise specified (PTCL-NOS) is a heterogeneous category, which includes nodal and extranodal T-cell lymphomas, according to the latest classification of tumours of the haematopoietic and lymphoid tissuesWorld Health Organization (2008) [2,3], representing almost $30 \%$ of all PTCL [1,4]. They are identified by a broad spectrum of morphological, immunophenotypic and molecular characteristics, in which the follicular variant is expressed in $<1 \%$ of the cases [2], and less frequent the T follicular helper cell (THF) phenotype that was formally recognized and included up to the 2008 classification [5].

This entity could be a diagnostic challenge, due to the broad classification of lymphoid neoplasms and the similarity in the clinical and histological characteristics of the PTCL-NOS variants, so, the immunophenotypic description and criteria is the key for its identification.

Our case highlights the clinical presentation of this hematopoietic disease, namely, the limitations for its diagnostic; in which the inmunophenotypic criteria and the microscopic features identify it. There are few studies that describe and support this new classification of $\mathrm{T}$ cell lymphoma phenotype, we need more clinical trials to review and recognize this entity.

\section{Case Report}

A 64-year-old male patient, from Santander, Colombia, with a to 1-year history of hyperpigmented and puriginous macular lesions, with initial diagnosis of psoriasis. He received management with topical corticosteroids, without improvement, instead of that; he presented progressive extension of the lesions, evolving to exophytic and tumoral lesions, with exudative surface in intertriginous areas, thighs and scalp (Figure 1). Physical examination revealed inguinal and axillary adenopathies, painless, without compromise of superficial or deep sensitivity, and absence of B symptoms (fever, weightloss, night sweats). Two months later, he developed ulceration of one of them in the left thigh, with superinfection by pseudomonas aeruginosa spp. isolated in secretion culture, antibiotic sensitivity test reported resistance to beta-lactamase inhibitors, fluoroquinolones, cephalosporins and aminoglycosides antibiotics, with sensitivity solely to carpanemens (meropenem, imipenem) (Figure 1d).
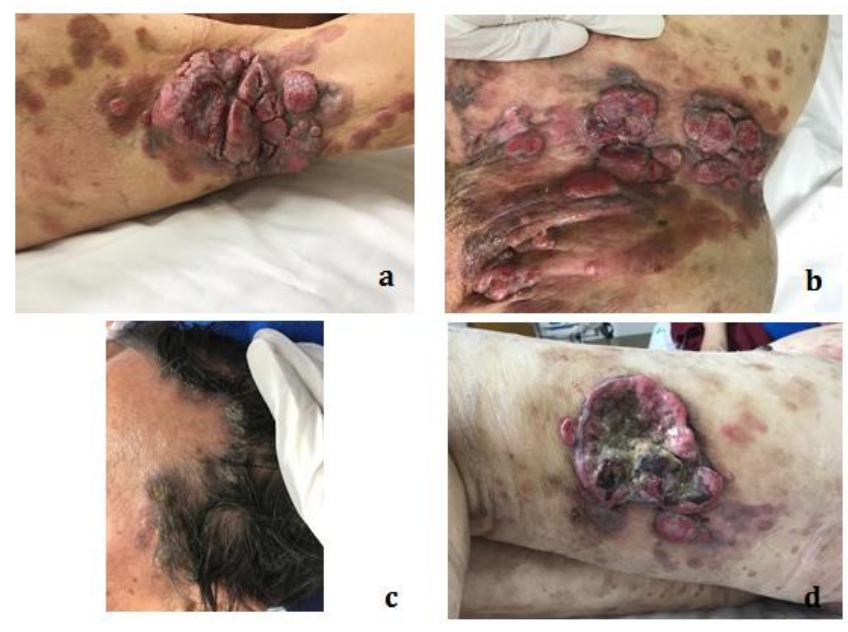

Figures 1(a-d): 1a: Axillary region with exophytic tumoral lesions. 1b: Exudative tumoral lesions in inguinal region. 1c: Desquamative tumoral lesions on the scalp. 1d: Superinfected lesion in left thigh.

Laboratory tests showed hypoalbuminemia, cytopenia (anemia, thrombocytopenia and lymphopenia) with leukocytosis and eosinophilia, elevated serum lactate dehydrogenase, later the laboratory reported acute renal injury and conjugated hyperbilirrubinemia. 
Imaging studies revealed cervical, axillary adenopathies and a left inguinal necrotic conglomerate lymph node, with hepatic nodular involvement suggestive of metastasis. In the histopathology and immunohistochemistry of axillary and inguinal lymph node biopsies, the diagnosis of peripheral T-cell lymphoma with $\mathrm{T}$ follicular helper cell phenotype was confirmed. The microscopy included medium-sized lymphoid cells, scarce cytoplasm and vesicular nucleus, with frequent mitotic activity and areas of necrosis. The T-cell markers were positive for CD3, CD4, CD5 and CD10, partially positive for PD1, negative for CD20, CD30 and CD8, with a tumor cell proliferation rate KI67 of $80 \%$ (Figure 2).
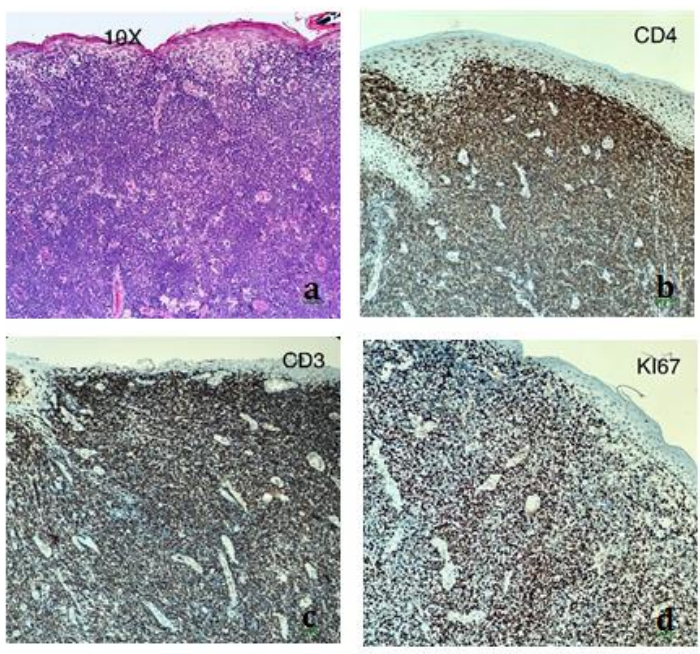

Figures 2(a-d): 2a: Ulceration of the epidermis, compromising the dermis up to subcutaneous cellular tissue. Mediumsized lymphoid cells with scarce cytoplasm and vesicular nucleus, frequent mitotic activity. 2b: Cell markers with diffuse positivity of tumor cells with CD4. 2c: Positivity CD3. 2d: Cell proliferation index KI67 of 80\%.

In less than fifteen days he presented respiratory distress, the chest radiography showed right basal pneumonia; the disease progresses to hypoxemic respiratory failure, endotracheal intubation was performed and transfer to the intensive care unit. He persisted with refractory hypoxemia and hypotension despite the use of vasopressors, antibiotics and invasive mechanical ventilation strategies; he died in a few hours.

\section{Discussion}

Peripheral T-cell lymphoma with $\mathrm{T}$ follicular helper cell phenotype is a variant of PTCL, which is characterized by the expression of CD4-positive markers and at least two antigens related to $\mathrm{T}$ follicular helper cell (PD1, CD10, BCL6, CXCL13, CXCR5, ICOS, SAP) [1,2], taking into account as prognostic markers the detection of KI67 and $\mathrm{EBV}+$ (Epstein Barr Virus) 1. This variant is characteristically rich in B cells [6], in relation to the function of $\mathrm{T}$ follicular helper cells in the germinal centers mediating the proliferation, differentiation and maturation of those B cells [4,7].

It is important to consider the close similarity of the $\mathrm{T}$ follicular helper cell phenotype with angioimmunoblastic T-cell lymphoma (AITL), the latter being a more frequent subtype, representing $1 \%$ to $2 \%$ of non-Hodgkin's lymphoma and $15 \%$ to $30 \%$ of PTCL-NOS. 2; both originate from $\mathrm{T}$ follicular helper cells and share the same cellular markers for its diagnosis, however AITL is distinguished by hyperplasia of follicular dendritic cells and proliferation of endothelial venules, and by the presence of B-cells with EBV positive as part of it cellular infiltrate $[2,8]$.

THF phenotype mainly affect elderly men, in the seventh decade, with an average age of 62 years old; it is usually not associated with B symptoms (fever, diaphoresis, weight loss), however they can occur in up to a third of patients [2]. The presence of adenopathies, 
mainly cervical, axillary and inguinal in $86 \%$ of cases. It has been described the extranodal involvement related to the positivity of the PD1 marker and in more advanced clinical stages, with hepatosplenomegaly in $71 \%$ of the cases, hematological and bone marrow involvement in $21 \%$, and skin lesions in $23 \%[5,9]$.

The most frequent laboratory tests are elevated serum lactate dehydrogenase, hypergammaglobulinemia, anemia or thrombocytopenia and positive combs test, other unusual findings may include hypereosinophilia and elevated serum $\operatorname{IgE}[5,9,10]$; however, these results are not pathognomonic of this lymphoid variant. Histologically there is an alteration of the ganglionic structure, with proliferation of small to medium size lymphoid cells, with some nuclei of irregular contours with dense chromatin, clear cytoplasm, without prominent polymorphic inflammatory infiltrate, and no proliferating vessels nor hyperplasia of the follicular dendritic cells [2,11]. The genetic study shares characteristics with AITL, including the mutations TET2, DNMT3A, RHOA, IDH2 [1,12], but in $20 \%$ of the cases the ITK / SYK mutation can be found only in AITL [8].

TFH phenotype is a variant of the PTCL-NOS recognized and included until 2008 in the new classification of lymphoid neoplasms of the WHO, with its own histological and immunophenotypic characteristics, despite of sharing a large part of these features with the AITL variant, including the same cellular origin. More studies that characterize this entity and allow a better diagnostic, prognostic and therapeutic approach are still required.

The authors declare that there is no conflict of interest regarding the publication of this article.

\section{References}

1. Coronado Poggio M, de la Cruz Vicente F, Gutierrez Garcia AM, Garcia Sancho AM, Novelli Canales S (2017) Guía GELTAMO para el diagnósico y tratamiento de los Linfomas T. Sociedad Española de Hematologia y Hemoterapia, España: Treelogy Medical Marketing S.L, pp: 8-11.

2. Swerdlow S, Campo E, Nancy LH, Jaffe E, Pileri S, et al. (2017) World Health Organization Classification of Tumours of Haematopoietic and Lymphoid Tissues. In: Swerdlow S, Campo E, Nancy LH, Jaffe E, Pileri S, Stein $\mathrm{H}$, et al. (Eds.), International Agency for Research on Cancer, $4^{\text {th }}$ (Edn.), France, pp: 185-187.
3. Swerdlow SH, Campo E, Pileri SA, Harris NL, Stein H, et al. (2016) The 2016 revision of the World Health Organization classi fi cation of lymphoid neoplasms. Blood 127(20): 2375-2391.

4. de Leval L, Bisig B, Thielen C, Boniver J, Gaulard P (2009) Molecular classification of T-cell lymphomas. Crit Rev Oncol Hematol 72(2): 125-143.

5. Hu S, Young KH, Konoplev SN, Medeiros LJ (2012) Follicular T-cell lymphoma: a member of an emerging family of follicular helper T-cell derived T-cell lymphomas. Hum Pathol 43(11): 1789-1798.

6. Ruiz SJ, Cotta CV (2015) Follicular helper T-cell lymphoma: A B-cell-rich variant of T-cell lymphoma. Ann Diagn Pathol 19(4): 187-192.

7. Buder K, Poppe LM, Brocker EB, Goebeler M, Rosenwald A, et al. (2013) Primary cutaneous follicular helper T-cell lymphoma: Diagnostic pitfalls of this new lymphoma subtype. J Cutan Pathol 40(10): 903-908.

8. Pileri SA (2015) Follicular helper T-cell-related lymphomas. Blood 126(15): 1733-1734.

9. Miyoshi H, Sato K, Niino D, Arakawa F, Kimura Y, et al. (2012) Clinicopathologic Analysis of Peripheral T-Cell Lymphoma, Follicular Variant, and Comparison With Angioimmunoblastic T-Cell Lymphoma: Bcl-6 expression might affect progression between these disorders. Am J Clin Pathol 137(6): 879-889.

10. Huang Y, Moreau A, Dupuis J, Streubel B, Petit B, et al. (2009) Peripheral T-cell lymphomas with a follicular growth pattern are derived from follicular helper $\mathrm{T}$ cells (TFH) and may show overlapping features with angioimmunoblastic T-cell lymphomas. Am J Surg Pathol 33(5): 682-690.

11. Agostinelli C, Hartmann S, Klapper W, Korkolopoulou P, Righi S, et al. (2011) Peripheral T cell lymphomas with follicular T helper phenotype: A new basket or a distinct entity? Revising Karl Lennert's personal archive. Histopathology 59(4): 679-691.

12. Maura F, Dodero A, Carniti C, Bolli N (2016) Biology of peripheral $\mathrm{T}$ cell lymphomas - Not otherwise specified: Is something finally happening? Pathogene sis 3(1): 9-18. 